\title{
EDUCAÇÃO, CONHECIMENTO E FINITUDE
}

Cezar Luís Seibt*

RESUMO: A complexidade da realidade humana não permite que a razão instrumental esgote explicativamente os elementos que compõe a realidade educacional. Surge a necessidade de uma atitude aberta $e$ atenta para compreender aquilo que se recusa e esconde na cotidianidade. A fenomenologia hermenêutica é consciência dos limites da racionalidade, postura vigilante, um desafio para a responsabilidade e criatividade na atividade pedagógica.

Palavras-chave: fenomenologia hermenêutica; conhecimento; finitude; ser-nomundo; educação.

RESUMEN: La complejidad de la realidad humana no permite que la razón instrumental agote explicativamente los elementos que conforman la realidad educativa. Surge la necesidad de una actitud abierta y atenta para entender lo que se niega y se oculta en la vida diaria. La fenomenología hermenéutica es consciencia de los límites de la racionalidad, un desafío a la responsabilidad y la creatividad en la actividad educativa.

Palabras claves: fenomenología hermenéutica; conocimiento; finitud; estar en el mundo; educación.

\section{Considerações Introdutórias}

Buscamos explicar as coisas, dar-lhes um fundamento, mostrar como funcionam, do que são feitas, qual a sua finalidade: produzimos teoria. Somos linguagem, nos movemos no horizonte de abertura que é sustentado e carregado pela palavra que, por sua vez, se articula na proposição. Quando a teorização se autonomiza e enrijece nos distanciamos daquilo que nos é mais próximo: nossa existência concreta, o mundo vivido, a experiência pré-teórica. O que é, é na teoria, na explicação. Não há problema nisso, a não ser que se tome a explicação (teoria) pela experiência singular (vivência); neste caso tendemos a 'reificar', engessar aquilo que originariamente é vivência. Tal se manifesta na educação na medida em que os conhecimentos adquiridos na tradição são tomados como se fossem verdade objetiva, produzidos fora das condições humanas, com referências de fora do mundo.

\footnotetext{
" Doutor em Filosofia - Docente de Filosofia da Educação da Faculdade de Educação e do Programa de Pós-Graduação em Educação da Universidade Federal do Pará - UFPA. E-mail: celuse@ ufpa.br 


\section{Revista Sul-Americana de Filosofia e Educação - RESAFE}

Queremos ler, a partir das noções de infinito e finito, como este modo habitual de considerar o conhecimento se cristalizou na tradição $e$ apontar a possibilidade de um retorno para o âmbito do prático (prático no sentido de fático, anterior à dicotomia entre teoria e prática). O modelo da infinitude se caracteriza pelo esforço em produzir uma instância última, objetiva para o conhecimento. Aparece nos esforços dos gregos, tal como em Platão, onde mundo inteligivel é a instância que garante o fundamento e sustenta o mundo sensível. Posteriormente se criam outros princípios a partir dos quais é possível deduzir a realidade (Deus, a subjetividade, empiria,...). Nesse processo é preciso ignorar o tempo, pressupor um horizonte estável, controlável, dominável, objetificável. As ciências modernas se desenvolvem sob esse fio condutor, inclusive as humanas. Para conhecer ou encontrar a verdade é preciso deixar de lado a historicidade.

Heidegger procura mostrar essa omissão do tempo. Mostra que na tradição metafísica o próprio ser foi tratado a partir do tempo enquanto presença, presente, e acabou sendo compreendido com fundamento objetificável. Re-pensar o ser a partir do tempo (como temporalidade) lhe confere outro sentido. Assume o caráter de horizonte, de abertura, de condição de possibilidade dos entes. Mas não é mais objetificável. Sustenta, mas se oculta no aparecimento dos entes. É um retorno para o ser-no-mundo, para a facticidade do ser humano. Somos históricos, concretos, situados, circunstanciais, temporais. A teoria é sempre produzida a partir deste horizonte prévio. Qualquer autocompreensão ou explicação dos entes enraíza-se no solo originário prático. Proposições, significados, teorias são sempre históricas e temporais, tal como o é o ser humano que as produz.

Enquanto ser-no-mundo o ser humano não pode mais pretender situar-se para além da abertura, como que posto fora do mundo, expectador de si mesmo, ou ocupando um lugar objetivo para contemplar a realidade e, assim, tornar-se totalmente transparente. Já sempre está numa compreensão de si mesmo e do ser, prévia aos seus comportamentos. Está limitado ao âmbito da interpretação (hermenêutica) e circularidade dentro da qual se desenvolvem as explicações, o conhecimento. Essa é a perspectiva da finitude, que parte da descrição (não de uma teoria) do modo como nos encontramos efetivamente no mundo, ser-de- 


\section{Revista Sul-Americana de Filosofia e Educação - RESAFE}

possibilidade, existência concreta, finita, e não mais como uma essência a-histórica e abstrata. O conhecimento tem também essas características. O processo educativo pode ser repensado a partir do reconhecimento e assunção da finitude. Tal postura nos reconduz para a responsabilidade inalienável pela nossa existência, pessoal e coletiva. Desafia para uma outra relação com o conhecimento.

\section{Da infinitude à finitude}

O ideal do conhecimento humano é a verdade, no sentido de estabelecer um saber necessário e universal. Ora, estabelecer um saber necessário e universal pressupõe, como já dissemos, a eliminação da historicidade e temporalidade. Ao menos, pretende que dentro da história se possa encontrar lugares seguros, que independem do curso do tempo. Parte da crença de que deve haver algo que permanece sempre idêntico a si mesmo, apesar do 'movimento' do tempo. Esse ideal alimentou a filosofia e também as ciências naturais e humanas. Também o ser humano foi compreendido como portador de uma essência a-histórica, que deve permitir a sua definição. Ou seja, a realidade deve poder ser objetivável, incluindo aí o próprio ser humano. Isso implica o estabelecimento de algum fundamento objetivo, que sempre se situa fora do tempo. Esse fundamento pode ser uma instância divina, a subjetividade, a razão, a ideia, ou mesmo a experiência empírica. Deverá haver sempre um lugar seguro e objetivo a partir do qual se possa falar e tomar posição, mantendo-se tranquilo e seguro de ter realizado a escolha certa. Este projeto trabalha, também, com a pressuposição da objetividade tanto do objeto como do sujeito do conhecimento.

O conflito que aparece na diferença entre o pensamento de Parmênides e Heráclito se resolve, na metafísica, para o lado da permanência e não da mudança. O conhecimento como opinião verdadeira justificada é aquele que estabelece, a partir de um ponto fixo, o que é e o que não é. Tal como Platão situa na Ideia o conhecimento verdadeiro, usando o recurso dos dois mundos, Aristóteles encontra, por detrás das impressões múltiplas e diversas dos sentidos, o conceito universal e abstrato. Platão, e a partir dele aquilo que chamamos de Metafísica, nos remete para uma possível participação no eterno e, com isso, convida à superação da contingência e finitude do singular. O supra-sensível e não-corruptível é o tipo de 


\section{Revista Sul-Americana de Filosofia e Educação - RESAFE}

conhecimento almejado tanto pela filosofia, como também pelas religiões e pela própria ciência (cf. DASTUR, 2002, p. 6). A verdade deve estar acima da contingência dos mortais conhecedores e, por isso, a morte deve ser relativizada para evitar o espanto e a impotência diante dela.

O que caracteriza essa posição é a assunção da infinitude como horizonte fundamental. Infinito significa exatamente a negação da finitude, a negação do tempo enquanto fluxo do passado em direção ao futuro, enquanto movimento $e$ transformação. Assume o presente como instância fundante, a tendência à presentificação, à preservação eterna do presente. Neste movimento se insere a busca da razão pura ou absoluta. Garante-se, assim, a existência de uma realidade objetiva a ser conhecida e um ente independente dela, que a conhece. Busca-se eliminar a interpretação e os pressupostos. Postula-se a ausência de pressupostos ou, ao menos, se faz de conta que o pesquisar e o conhecimento são frutos da total assepsia e ausência de elementos não controláveis.

Segundo Loparic, "o infinitismo é o princípio organizador da metafísica ocidental" (LOPARIC, 2004, p. 9). Nele buscam-se causas e verdades que sejam infinitas, que vigorem incondicionalmente, ou seja, ele é centrado no princípio do fundamento. Através desse princípio "visa-se achar um antídoto universal para a falta, a transitoriedade e a particularidade, os três elementos constituintes da finitude humana, todos assinalados pela dor" (LOPARIC, 2004, p. 9). Na busca da solução para a falta, a transitoriedade e a particularidade, a tradição metafísica interpretou o ser como infinito. Tal interpretação se fixou e conduziu a humanidade, pela vontade de poder, para o domínio de todas as coisas pela manipulação calculadora.

A solução para esse problema se dará "caso o projeto infinitista [...] for reconhecido como um descaminho perigoso e substituído pelo caminho de retorno à finitude do ser" (LOPARIC, 2004, p. 13). Neste processo entra o reconhecimento de que há um ocultamento no desocultamento, um sentido do ser para além do ente, ou seja, será necessário "reconhecer, na positividade do fundamento tradicional, a negatividade do retraimento possibilitador" (LOPARIC, 2004, p. 14). 
Corre-se, neste caso, o risco do descontrole e da insegurança, mas retorna-se para casa, para a finitude da existência humana, para uma ontologia da finitude.

$\mathrm{Na}$ cotidianidade e na tradição a finitude precisou ser exorcizada. O infinito exorciza a morte, afasta o seu poder. A partir do horizonte do infinito a morte é dominada e, com ela, a própria realidade. Mas a morte é inapreensível, não pode ser circunscrita, não pode ser medida, não permite ou se presta para nenhum domínio, a não ser que alguém ocupe o lugar do infinito e o faça a partir daí. Com isso estamos dizendo que a metafísica, para poder garantir o domínio dos entes e o funcionamento da realidade de forma controlável e estável, opta pela infinitude. Isso significa que ela opta pelo intemporal, pelo supra-sensível, pelo nãocorruptível, pelo estável, pelo controle. A ciência e a técnica modernas e contemporâneas representam bem o resultado desse processo e da pretensão de domínio e controle total da realidade.

A perspectiva da infinitude expulsa a capacidade de espantar-se e admirarse, que deu origem à própria filosofia na Grécia. Já o modelo da finitude mantém a capacidade para o mistério e, portanto, para a atitude de espanto e admiração. Com a consciência da morte, daquilo sobre o qual não temos efetivamente domínio, ficamos abertos para "a desmedida daquilo que não tem experiência possível" (DASTUR, 2002, p. 9). O escoamento do tempo é irreversível, aniquilador das individualidades e também das teorias. Todas as técnicas e saberes não conseguem evitar que o presente escoe entre os dedos e ceda espaço para o 'depois' que constantemente se aproxima. O domínio do homem não se estende para o âmbito da morte. Podemos retardá-la, mas não evitá-la. Podemos viver como se não fossemos morrer, mas isso não retira a morte do caminho, somente ameniza a consciência da sua presença.

Heidegger, nos seus estudos sobre mística cristã, sobretudo interpretando São Paulo, Agostinho, Eckhart, Boaventura e Lutero, descobre que "o sentimento cristão nada mais é que a experiência da temporalidade finita enquanto esta se baseia na consciência da incerteza constante, essencial e necessária do momento da morte" (DASTUR, 2002, p. 23). Essa experiência mística ainda não enquadrada em molduras teóricas (teológicas e filosóficas) lhe serviu de base para "pensar fora 
da tradição objetivista", para acessar "a experiência cristã originária", "caminho para o solo originário da vida fática" (HEBECHE, 2005, p. 14). Nos escritos 'de juventude' destes autores cristãos Heidegger quer desencobrir "uma experiência de vida que não havia ainda sido encoberta pelo dogmatismo e pelas instituições religiosas" (HEBECHE, 2005, p. 14).

\section{Finitude, Facticidade e Circularidade}

Por isso, Heidegger "encontra-se em luta contra a objetivação da vida fática" (HEBECHE, 2005, p. 40). Essa objetivação liga-se à objetivação do mundo e, portanto, necessita de uma desconstrução da noção de mundo tradicional para alcançar a vida fática. É preciso desconstruir a pesada estrutura teórica que abafa, através da universalidade e necessidade conceitual, a experiência originária, a vida em sua facticidade. Retomar o sentido originário que se esvaziou na representação histórica do fato originário exige "situar-se num âmbito anterior a toda reflexão teorizante" (HEBECHE, 2005, p. 59). Neste âmbito anterior encontra-se "o solo fático das ciências do espírito" (HEBECHE, 2005, p. 63). Neste trabalho, em que é preciso realizar uma desconstrução da tradição encobridora, Heidegger pretende recuperar o solo para reconduzir o ser humano para si mesmo, efetivamente, ou seja, para o problema fundamental da sua existência, para a vida humana como tarefa sempre inacabada, histórica e finita, num exercício constante, mas sempre provisório. Isso foge das elaborações teóricas, preceitos ou leis universais e necessárias, e confere novamente vitalidade à existência histórica. Quando a historicidade deixa de ser um estorvo e um peso para o Dasein, quando este deixa, portanto, de fugir para o eterno $e$ infinito, ele assume a responsabilidade $e$ o caráter incompleto e inesperado da existência finita.

Neste sentido, a metafísica, que representa a opção pela infinitude, tem dificuldades de enfrentar a morte e elabora alternativas teóricas e técnicas para manter o olhar afastado da possibilidade final, através do cultivo da impessoalidade, inclusive no que tange ao morrer. É da "imortalidade provisória que vivemos a princípio e o mais das vezes, o que implica que a vida humana não pode se estender largamente a não ser que ela se esquive da morte" (DASTUR, 


\section{Revista Sul-Americana de Filosofia e Educação - RESAFE}

2002, p. 76). Mas a fuga da morte é necessária para a manutenção da cotidianidade, da existência normal. Já o discurso fenomenológico "não promove nenhuma 'ultrapassagem' ou ' superação' da morte e não oferece nenhuma transcendência suscetível de neutralizá-la” (DASTUR, 2002, p. 58). A morte introduz o caráter de finitude no conjunto dos fenômenos, como que o fundo a partir de onde eles se destacam. Ela torna-se, assim, constitutiva do ser do ser humano e marca todas as suas manifestações.

A finitude reconduz o ser humano para si mesmo, lugar do fundamento enquanto abismo, cortando a possibilidade de determinações exteriores, de um olhar objetivo e distanciado de si mesmo para contemplar-se. A angústia lhe revela a finitude, a constante iminência da morte. A morte é sempre possível, iminente, porque não advém de fora, mas é constitutiva da existência. Dastur nota que "o ser mortal que é o Dasein de modo algum é livre para se fazer finito, já que, sendo lançado no meio do existente e não encontrando a ele mesmo na origem de seu próprio existir, ele é desde sempre finito" (DASTUR, 2002, p. 99). A finitude lhe confere a responsabilidade pelo seu ser.

Essa finitude originária não é derivada da infinitude, a compreensão do ser finito não pressupõe uma relação com o infinito, o perfeito. O finito não procede de algo exterior, e nem mesmo a infinitude. A infinitude não é uma luz que vem de fora, mas "a manifestação da necessidade de compreensão de um existente que é destinado a residir no mundo e obrigado a acender ele mesmo o fogo que iluminará as paredes da sua prisão" (DASTUR, 2002, p. 112). Aquilo de que se predica ser infinito é elaborado, produzido, iluminado a partir da finitude radical do existente no qual acontece a abertura do ser. Podemos até dizer que a própria infinitude, neste caso, é finita. Ser-no-mundo é finitude que, pela abertura, projeta o infinito, mas o deixa marcado com o selo da finitude. A transcendência não decorre da infinitude e não encontra nela seu modelo originário mas, ao contrário, a transcendência se dá na e a partir da finitude.

Ser e Tempo é uma obra na qual se parte da finitude humana para questionar o ser. A transcendência acontece na finitude, é instaurada pela finitude $e$, por isso, a transcendência se fundamenta e se origina nela. A transcendência é 
"a esfera em que se move todo conhecimento" (STEIN, 1976, p. 18). Por isso "buscar o fundamento do conhecimento é interrogar por aquilo que está na origem da transcendência" (STEIN, 1976, p. 18), ou seja, pela finitude. "Não há transcendência sem finitude" e a "finitude está condenada à transcendência", de forma que "é a finitude do homem que lhe impõe passar pela transcendência para ter acesso a si mesmo e aos entes" (STEIN, 1976, p. 12).

A finitude, na Metafísica, soa como negação e imposição de limite. Não é este o caso no pensamento de Heidegger, pois o ser somente pode ser experimentado assim (Cf. STEIN, 2001, p. 123). O ser, agora possível na e pela transcendência do Dasein, está ligado à facticidade, à ambivalência do velamento e desvelamento, ao nada. A facticidade é o lugar incontornável, a partir de onde se realiza a compreensão, numa circularidade que não tem condições de eliminar seus pressupostos, mas que opera somente dentro do horizonte liberado por estes. Essa estrutura circular é a característica fundamental da finitude (Cf. STEIN, 2001, p. 289). Ser, agora ligado ao tempo, não pode ser interpretado a partir do infinito, tal como na tradição. O infinito é negação do tempo. Não é o originário, mas é derivado da existência temporal do Dasein. O infinito, dele somente se pode falar a partir da compreensão do ser e esta é a abertura na qual o ser se 'mostra' velandose na manifestação do ente. Somente no horizonte da compreensão do ser algo pode ser conhecido, inclusive o infinito e eterno. A infinitude do ser da Metafísica é substituída pela finitude do ser.

Dessa forma "a compreensão do ser é finita, enquanto se manifesta na finitude do ser-aí, mas, tal finitude é a positiva possibilidade de o ser se mostrar aquilo que é, enquanto se vela. Na própria manifestação o ser se vela" (STEIN, 2001, p. 385). A compreensão do ser é o fundamento não mais metafísico, sem apelo ao infinito ou a um ente último e estável, mas abertura que se vela nos entes que manifesta. Mantém-se a diferença ontológica e por isso se pode afirmar que

Heidegger é o filósofo da finitude. O ser para Heidegger é o signo da finitude na relação que estabelece com o homem. A ontologia é o índice da finitude. A filosofia é a tarefa da finitude. O ser é finito para o homem. O homem é finito porque está condenado ao ser em sua relação com os entes. 
Por isso Heidegger permanece vigilante na diferença imanente, na circularidade da interrogação pelo ser (STEIN, 2001, p. 389).

O círculo hermenêutico e a diferença ontológica são dois teoremas que resultam do reconhecimento da finitude do ser humano, da sua facticidade, do fato de que ele já sempre compreende o ser e compreender a si mesmo. O pensamento de Heidegger sobre a realidade e o conhecimento está, por isso, inserido neste horizonte. O conhecer é um modo de ser do Dasein, e tem as características deste modo de ser.

A finitude mostra que o ser humano está afetado pela morte em cada momento de sua existência e por isso Heidegger pode afirmar que ele é ser-para-amorte (Cf. 1998, 2a Seção). Ele é mortal, essencialmente finito, nunca completo, pois tem sempre algo pendente, até que a morte efetivamente aconteça, eliminando o ser-no-mundo, o ser de possibilidade. A vida, que transcorre sempre incompleta, chegará ao seu fim. Mas não é simplesmente por ter um fim que o Dasein é finito; ele está marcado pela limitação desde o seu início. A finitude o acompanha desde o momento em que começa a existir. Todo seu ser e agir são índice da finitude.

Diante do fato de sermos finitos podemos fugir ou assumir nossa responsabilidade. Quando Heidegger se refere à temporalidade e ao tempo, também está em jogo uma postura diante da finitude. O tempo, tal como compreendido no modelo metafísico, é o tempo do eterno presente, ou da sucessão de momentos pontuais, tempo do relógio. Esse tempo é o tempo cotidiano, inautêntico e impróprio. Ampara-se na perspectiva do infinito. Já o tempo como temporalidade foge à objetivação e matematização, é o tempo originário, finito. Do ponto de vista da temporalidade, a morte retira o Dasein do envolvimento ocupado com as coisas do mundo entorno, da existência cotidiana, na qual não há individualização, pois impera o impessoal, o "Man". Falando da temporalidade, Ree afirma que "viver nossas vidas como tempo-do-agora é 'fugir' perante a finitude, ou 'desviar os olhos' dela. Ao viver no 'agora' transformamonos no próprio-impessoal (2000, p. 53). 
Ree também nota que a morte "nos 'individualiza' de forma mais absoluta" (2000, p. 49). A morte nos retira da coletividade na qual ninguém é responsável, onde reina a sutilidade da vida de rebanho, como diria Nietzsche. Isso porque a própria morte é algo que somente pode ser experimentada por mim mesmo. Ninguém pode viver a minha morte. A minha morte é somente minha. A morte de outro indivíduo não permite que eu experimente o próprio morrer. Ela não pode ser objetificada ou objetivada e sempre foge às tentativas de manipulação $e$ enquadramento.

A finitude caracteriza o modo de ser do Dasein no tempo: o nascimento é o momento radical e fundamental no passado que marca o início do ser-no-mundo $e$ a morte estabelece o fim, um limite para ele no futuro. Viver no presente, 'como se' não houvesse esse início e esse limite final, garante a sensação de eternidade, de constante adiamento, de ausência de responsabilidade pessoal, ou seja, uma vida vivida na cotidianidade.

\section{Postura da fenomenologia hermenêutica}

A superação do tempo cronológico conduz à reconquista do tempo próprio, do tempo condição de possibilidade do tempo mensurável. O tempo originário, a temporalidade, tem íntima relação com o ser e, portanto, com o ser-aí, o Dasein. A transcendência do Dasein é temporal, não se estrangula no presente, mas é tradição que se projeta para frente, para o futuro, no agora. Não haveria transcendência se não fosse essa temporalidade, o Dasein estaria grudado no aqui e agora. É a finitude que faz do homem um Dasein e, como fato originário, conduz para a questão do ser em geral (Cf. NUNES, 1992, p. 164 e 165). O trabalho hermenêutico é, então, uma rememoração da finitude, contra o esquecimento metafísico. A compreensão do ser que caracteriza o ser do Dasein é a raiz da finitude do homem.

Com a analítica existencial, Heidegger, como salienta Apel, confere "validade à finitude" e "pertinência à história" (2005, p. 58). E Gadamer nota que "a finitude do próprio compreender é o modo como e onde a realidade, a resistência, o absurdo e incompreensível alcança validez. Quem leva a sério essa 


\section{Revista Sul-Americana de Filosofia e Educação - RESAFE}

finitude tem de levar a sério também a realidade histórica" (1999, p. 24). A recordação da finitude "descarta o absoluto e a totalização superadora do fim por meio do intelecto - a imortalidade spinozista do conhecimento e a infinitude da verdade reincorporada pela razão hegeliana -, também descarta o poder de principiar e de começar absolutamente, que o idealismo atribui ao sujeito" (NUNES, 1992, p. 156). E, por isso, tudo aquilo que o ser humano conhece e faz "tem sempre como prelúdio a compreensão do ser inerente ao seu Dasein cuidadoso, que recebe do tempo a possibilidade de fazer e de conhecer" (NUNES, 1992, p. 156).

Como já dissemos, é da finitude que emerge o ser, não de algum modelo transcendente, absoluto ou infinito. O ser humano existe compreendendo, está envolvido simbioticamente com as coisas, com o mundo. A fenomenologia, enquanto exercício de retorno às coisas elas mesmas, se caracteriza pela compreensão, pelo inelutável envolvimento originário com a facticidade. A ontologia terá como ponto de partida a vida fática, será hermenêutica, interpretação a partir de um já sempre compreender o mundo. Não há instância externa ao envolvimento compreensivo para sustentar uma teoria com pretensões de objetividade. Movemo-nos dentro do círculo compreensivo, já sempre praticamente envolvidos compreendendo o ser.

A fenomenologia hermenêutica de Heidegger aparece como alternativa para o pensamento objetivista e representacional ocidental sustentado a partir da relação sujeito e objeto, tomando como ponto de partida o compreender, os pressupostos fáticos, originários, práticos, cotidianos do Dasein. Tem o potencial de superar tanto a perspectiva da objetividade como da subjetividade. Nela revelase a própria vida humana, o Dasein, como fundamento histórico e contingente e fonte de todas as interpretações. A interpretação do Dasein revela a sua incapacidade de total transparência, sua consciência finita, seu lugar dentro da abertura da linguagem, sua já sempre intersubjetividade. Sendo no tempo e não podendo elevar-se para fora dele, não pode nunca dispor absolutamente do seu

ser e do ser dos demais entes do mundo. Não pode, por isso, separar sua interpretação do ato de compreender a realidade e a si mesmo. Não há distância 
entre interpretante e interpretação que permita critérios objetivos para a verdade do conhecimento. A abertura do ser, o sentido do ser envolve qualquer comportamento humano. A estrutura do ser-no-mundo constitui o transcendental histórico, a condição de possibilidade para qualquer sentido. Estamos irremediavelmente ligados à nossa existência, presos ao círculo hermenêutico, não podemos nos afastar de nós mesmos para pensar. O trabalho da fenomenologia hermenêutica mostra que o ser se mantém escondido, oculto, por causa do predomínio do teórico, que compreende a partir da relação com os objetos.

Aquilo de que irá tratar a fenomenologia em sentido fenomenológico será o ser. Em primeiro lugar do ser deste ente que está na abertura e que é 'aí', a partir de onde tem sentido falar em significatividade, mas cujo ser não está acessível por causa dos encobrimentos produzidos pela tradição. Não é, desta forma, uma investigação desenraizada do ser, mas uma radical imersão na facticidade, no ser enquanto o mais efetivo e indepassável horizonte em que o ser humano se move enquanto Dasein.

A filosofia, diante da tendência naturalista e cientificista que domina o cenário intelectual, encontra no retorna à vida, às experiências diretas da vida, um significativo campo de investigação para si mesma. Cortando a blindagem teóricocientífica e mesmo a da filosofia transcendental da modernidade, surge a intuição de um compreender e captar que precedem o discurso teórico. A filosofia volta a aventurar-se no perigoso e incontrolável acontecer da vida, fora do âmbito da certeza, segurança e objetividade. Essa atitude pode também inspirar outras posturas e reflexões no campo da educação, da pedagogia.

\section{Pedagogia da finitude - Considerações finais}

$\mathrm{O}$ que dissemos nos leva a pensar na possibilidade e necessidade de uma pedagogia da finitude como resposta aos desafios resultantes desta visão de ser humano e da sua relação com o mundo. Tal reflexão pedagógica pode desapontar os ouvidos acostumados aos contornos bem definidos de sistemas explicativos que, a partir de algumas premissas teóricas razoáveis, avançam apresentando os entes envolvidos de forma objetiva. As ideias resultantes de uma reflexão de cunho 
fenomenológico-hermenêutico não constituem nenhum sistema fechado $e$ asséptico, mas resultam de um reconhecimento fundamental: não temos possibilidade de tomar distância de nós mesmos e nem dos objetos com os quais estamos envolvidos. Não é, por isso, nenhum tipo de receituário pedagógico que possa resolver problemas pontuais ou trazer soluções para os conflitos dentro da relação educativa. Temos uma primeira constatação importante: movimentar-se dentro desse paradigma não produz tranquilidade e comodidade mas, ao contrário, reconduz para a condição humana de ser-no-mundo, produtora de sentido a partir da relação, de dentro da relação. Dentro dele nos sentimos desamparados dos consolos que a tradição providencia e nos vemos entregues a nós mesmos. Não se pode esperar uma nova teoria pedagógica fechada, mas uma renovada capacidade de experimentar o fenômeno educativo e de responder criativamente a ele. Possivelmente, uma capacidade para fazer a experiência da experiência, o que significa o desenvolvimento da capacidade de desvencilhar-se da captura a que estamos submetidos cotidianamente na nossa lida com os entes. É uma espécie de distanciamento em relação ao ente para experimentar o ente como ente, ou seja, o ser do ente, sem que isso represente a conquista de uma nova objetividade, resultado da produção de um porto seguro para a observação.

A fenomenologia hermenêutica é, antes de tudo, uma postura e disposição diferente, resultado da desconstrução dos conceitos que na tradição petrificaram os fenômenos e fizeram com que se perdesse contato com a vitalidade e vigor originário da experiência. Essa postura aponta para a possibilidade de "compreender a racionalidade que opera na prática educativa" (HERMANN, 2002, p. 11) para além daquela que se caracteriza pela explicação causal e pelo método empírico-formal. É um resgate do processo de instauração de sentido que acontece na medida em que estamos sempre envolvidos compreensivamente com o mundo dos entes. Além do mundo dos entes, há a mundanidade do mundo, o mundo como um horizonte de sentido dentro do qual os entes podem ser isto ou aquilo, onde são algo e não não-são. Nossa condição humana é de intérpretes, já sempre em movimento dentro de um horizonte de sentido que antecipa as possibilidades. 


\section{Revista Sul-Americana de Filosofia e Educação - RESAFE}

Somos, por isso, finitos, imersos na dinâmica do tempo e tudo que fazemos $e$ conhecemos também se encontra marcado por essa condição primária.

Não é um método que poderá nos salvar deste estado. Há que reconhecer a impossibilidade de transpor o mundo, de saltar para fora dele com a pretensão de alcançar um posto objetivo. Estamos sempre envolvidos num círculo interpretativo insuperável. Isso não leva a uma postura de resignação e pessimismo, mas ativa nossa responsabilidade fundamental pelo que fazemos de nós, pelo nosso destino. Não temos outro modelo, mas a possibilidade de um novo modo de estar no mundo, aberto, criativo, responsável, mais próprio e autêntico. A complexidade do fenômeno humano exige essa postura, embora sem eliminar os esforços metódicos das diversas ciências, mas lembrando-as da sua dependência de uma compreensão prévia, da limitação da tendência moderna da especialização e circunscrição que produzem um reducionismo em relação ao objeto.

O resultado é, entretanto, a perda de controle, a redução da capacidade de domínio com que sonhou a modernidade. O conteúdo ou conhecimento, aparentemente objetivo e justificado em bases sólidas, passa a ser visto a partir da totalidade do projeto humano dentro do qual é produzido. A relação com o conhecimento passa de um estado de submissão a um estado de assunção da condição de produção humana, resultante da relação ou lida com os objetos $e$ eventos, de forma circular. Há sempre uma compreensão prévia ou précompreensão, que é como uma clareira dentro da qual as coisas tem sentido, a partir da qual se estabelece a relação. Essa constatação encaminha para a superação da separação objetificadora, a relação sujeito e objeto. Qualquer conhecimento é temporal, histórico, produzido dentro do círculo hermenêutico. Os conhecimentos ou conteúdos do processo educativo passam a ser vistos como modos possíveis de ser, e a metodologia será atenção constante e criativa, abertura para o que se manifesta dentro do projeto humano finito.

Neste processo a educação ganha em auto-esclarecimento, em responsabilidade e criatividade. Suas próprias bases, fundamentos e justificações se esclarecem na medida em que ela se põe em diálogo e supera a dimensão técnicocientífica, revelando sua dimensão criadora e a incapacidade de dominar 
totalmente o objeto. Por essa atitude resgata-se uma capacidade de abertura da experiência educativa, como afirma Hermann (2002, p. 85), disposta ao diálogo, ao exame dos próprios preconceitos e à autocrítica, embora sem poder alcançar a transparência total. Apesar de com isso se desestabilizar o "arcabouço teórico do projeto pedagógico moderno" (HERMANN, 2002, p. 88), não se oferece uma resposta ou teoria que possa abarcar novamente todas as situações pedagógicas. A atividade humana é rica e sujeita ao tempo, de forma que precisa sempre de novas respostas, de novas reflexões que levem em consideração a especificidade $e$ singularidade dos acontecimentos. Exige uma atenção sempre renovada, uma postura de admiração, espanto e disposição para compreender e responder aos apelos que a vida e a educação apresentam sempre novamente.

\section{Referências bibliográficas}

APEL, Karl-Otto. Transformação da filosofia I. Trad. Paulo Soethe. São Paulo: Edições Loyola, 2005.

DASTUR, Françoise. A morte - ensaio sobre a finitude. Trad. Maria T. Pontes. Rio de Janeiro: DIFEL, 2002.

GADAMER, Hans-Georg. Verdade e Método. Trad. Flávio Paulo Meurer. Petrópolis: Editora Vozes, 1999.

HEBECHE, Luiz. O Escândalo de Cristo - ensaio sobre Heidegger e São Paulo. Ijuí: Ed. UNIJUÍ, 2005.

HEIDEGGER, Martin. Ser y Tiempo. Chile: Editorial Universitaria, 1998.

HERMANN, Nadja. Hermenêutica e Educação. Rio de Janeiro: DP\&A, 2002.

LOPARIC, Zeljko. Ética e finitude. $2^{a}$ edição. São Paulo: Editora Escuta, 2004.

NUNES, Benedito. Passagem para o poético - filosofia e poesia em Heidegger. São Paulo: Ática, 1992.

RÉE, Jonathan. Heidegger. São Paulo: UNESP, 2000.

STEIN. Ernildo. Melancolia. Porto Alegre: Ed. Movimento, 1976.

. Compreensão e Finitude - estrutura e movimento da interrogação heideggeriana. Ijuí: Unijuí, 2001. 